\title{
Kayseri Müzesi'nden Yayımlanmamış Bir Portre Baş ${ }^{1}$ An Unpublished Portrait Head From Kayseri Museum
}

\author{
Yaşar ARLI*
}

\section{$\ddot{O} \mathbf{z}$}

1964 yılında özel bir şahıs tarafından gerçekleştirilen bir evin temel kazısında ele geçen kadın başı, günümüze kadar yayımlanmamıştır. Buluntu yeri ve yapı bağlantısı bilinmeyen Kayseri eserini, yalnızca saç modası ve fizyonomik özelliklerden yola çıkarak tarihlendirmek zor olsa da gerçekleştirdiğim karşılaştırmalar ve değerlendirmelerle kadın başına, bir dönem ve kimlik önerisi getirilmeye çalışılmıştır. Arkeoloji literatürüne kazandırmak için kaleme aldığım Kayseri eserindeki kuaförlük modası, dolgun yüz ile göz bebeği ve irisin işlenmemesi kadın başını, tarihlendirmemize olanak sağlayan tanımlayıcı özelliklerdir. Kayseri Müzesi'nde korunan eserdeki "Ceres Tipi” saç modası, Iulius - Claudiuslar Hanedanlığı ve Hadrian dönemlerindeki resmi ve özel kadın portreleriyle yakın benzerlik göstermektedir. Yalnızca Kayseri başındaki kuaförlük modası, Iulius Claudiuslar Hanedanlığı dönemlerindeki saç modasını anımsatmasına rağmen patetik ifadenin verilmeyişi kadın başını, bu dönemin üslup özelliklerinden ayırmaktadır. Kadın başındaki saç modası, ayrıca Hadrian dönemi kadın portrelerindeki kuaförlük modasıyla da büyük benzerlik gösterse de Kayseri portresinde, Iulius Claudiuslar Hanedanlığı dönemleri eserlerinde olduğu gibi Hadrian dönemi portrelerinde de gördüğümüz fizyonomik özelliklerin idealize edilerek verilişi yer almamaktadır. Fakat aynı zamanda eserde patetik ifadenin yer almayışı, "Ceres Tipi" saç modası ve göz bebeği ve irisin işlenmeyişi de kadın portresini, fizyonomik özelliklerin tam olarak idealize edilmediği Erken Hadrian dönemine tarihlendirmemize mümkün kılmaktadır. Çalışmamda da "Ceres Tipi” kuaförlük modasının görüldüğü her iki dönemle, Kayseri başını karşılaştırarak eserin tarihlendirilmesi, kimlik çalışması ve önerdiğim dönemin gerekçeleri detaylı bir şekilde verilmek istenmiştir.

Anahtar Kelimeler: Kayseri Müzesi, Kadın Başı, Erken Hadrian Dönemi.

\begin{abstract}
The female head which was uncovered during foundation excavation of a house by a person in 1964 has not been published until today. Although it is difficult to date Kayseri piece, of which finding place and building connection are not known, based on only hair fashion and physiognomical features, it is tried to bring forward a proposal of period and identification to the female head by my evaluations and comparisons. The hairdressing fashion, plump face, the lack of depicting pupil and iris on Kayseri piece which I have written to add to the archeology literature are defining features that allow us to date the female head. "Ceres Type" hair fashion on the piece preserved in Kayseri Museum, closely resembles formal and private female portraits in Julio-Claudian Dynasty and Hadrian periods. Although only the hairdressing fashion on Kayseri head reminds the hair fashion in the periods of Julio-Claudian Dynasty, the lack of patetic expression distinguishes the female head from the stylistic features of this period. Though the hair fashion on the female head is also very similar to the hairdressing fashion on the female portraits of Hadrian period, the portrait of Kayseri does not include the expression of the physiognomic features by idealizaton seen in the portraits of Hadrian period as in the pieces of Julio-Claudian Dynasty. However, at the same time, the absence of a patetic expression on the piece, the "Ceres Type" hair fashion and the lack of depicting the pupil and iris make it possible to date the female portrait to the Early Hadrian period when the physiognomical features were not fully idealized. In my study, it has been aimed to give detailed information about the date of the piece, identification study and the reasons for the period I proposed by comparing the head of Kayseri with both periods in which the "Ceres Type" hairdressing fashion was seen.
\end{abstract}

Keywords: Kayseri Museum, Female Head, Early Hadrian Period.

\section{Giriş}

Buluntu yeri ve ele geçtiği yapı kompleksinin bilinmediği yerlerden ortaya çıkartılan portrelerin tarihlendirilmesi ve kimlik tanımlaması oldukça zordur. Bu yüzdendir ki herhangi bir yapı ya da yazıtla desteklenmeyen Kayseri portresinin resmi ya da özel bir şahsa ait olup olmadığını belirlemek de saç modası ve üslup özellikleriyle açıklanmaya çalışılmıştır. Bu yapılırken de uluslararası portre araştırmacılığında kabul edilen çalışma metodu

\footnotetext{
${ }^{1}$ Kadın başını, çalışmama izin veren Kayseri Müze Müdürlüğü ve bünyesindeki Sayın Gökhan Yıldız’a sonsuz teşekkürlerimi sunarım.

*Arş. Gör., Akdeniz Üniversitesi, Edebiyat Fakültesi, Arkeoloji Bölümü, yasararli@akdeniz.edu.tr.
} 
kullanılmıştır. Kayseri Müzesi'nde korunan kadın başının sırasıyla durum, tanım ve değerlendirmesi gerçekleştirilmiştir. Yapmış olduğum değerlendirmeler neticesinde de günümüze kadar yayımlanmamış Kayseri başı, arkeoloji bilimine kazandırılmıştır.

\section{Eserin Envanter Bilgileri}

Kadın Başı (Lev. I)

Kayseri Arkeoloji Müzesi (Env. No. 4785)

Kayseri.

B. Y $30 \mathrm{~cm}, \mathrm{~B} . \mathrm{G} 22,5 \mathrm{~cm}$.

İnce tanecikli beyaz mermer.

Erken Hadrian Dönemi.

Alındığı Kaynak: Yayımlanmamıştır.

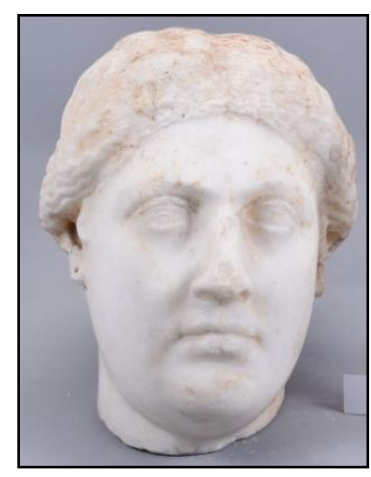

\section{Durum}

Baş, boyundan itibaren kırık ve eksiktir. Yüzde yer yer aşınma ve zedelenme yer almaktadır. Kulaç uçlarında küçük kırıklıklar görülmektedir. Burun ucunda ufak bir kopma mevcut olup, eserde renklenme ve kabuklanma söz konusudur.

\section{Tanım}

Günümüze kadar oldukça iyi durumda koruna gelen portre baş, yetişkin bir kadına ait olmalıdır. Gözler, uzağa bakmaktadır. Hafif dalgalı ince saç bukleleri, alın merkezinden her iki yana ayrılarak başın arka kısmında ense kökü üzerinde sonlanmaktadır. Başın tepe kısmındaki saç bukleleri ise daha hacimsiz ve yüzeyseldir. Alın, dardır. Kaşlar, ince ve yay şeklindedir. Göz kapakları, badem şeklindedir. Göz akları, göz pınarlarına doğru uzamaktadır. Üst göz kapağı alttakine oranla daha etlidir. Göz bebeği ve iris, işlenmemiştir. Burun, burun kökünden itibaren düz ve küçüktür. Burun kanatlarının her iki yanından aşağıya doğru inen yüzeysel ve kısa çizgiler yer almaktadır. Yüz anatomisine uygun olmayan kulaklar, gerçekçi değildir. Kulak uçlarında küpe delikleri görülmektedir. Her iki kulak önünde serbest bırakılmış aşağıya doğru uzanan kısa saç bukleleri mevcuttur. Üst dudak alanı dardır. Ağız, hafif bir şekilde kapalıdır. Üst dudak, alt dudağa oranla incedir. Yuvarlak çene, yağlıdır. Yüz, yuvarlak ve dolgundur. Gerdan, yağlıdır. Başın arka kısmında düz bir şekilde bırakılmış kısımda dübel izleri görülmektedir. Bu dübel izleri de kadın başını, bir yere sabitlemek ya da boyun desteği için kullanılmış olmalıdır. Baş, bir portre büst ya da heykele aittir.

\section{Eserin Yorumlanması}

Kadın başındaki alın merkezinden her iki yana ayrılarak ense kökü üzerinde sonlanan hafif dalgalı saç bukleleriyle şekillendirilmiş saç modası "Ceres Tipi” olarak tanımlanmaktadır (Özgan, 2013, s. 164). Iulius - Claudiuslar Hanedanlığ 1 döneminde resmi ve özel kadın portrelerinde (Rumpf, 1941, lev. 1; Sadurska, 1972, lev. 6; Erkoç, 2012, lev. 77) görülen bu kuaförlük modası Hadrian döneminde de (İnan ve Rosenbaum, 1979, s. 248 lev. 158 res. 1, 2, 3; Fittschen ve Zanker, 1983, s. 10, 11 lev. 12) kullanılmıştır. Iulius Claudiuslar Hanedanlığı döneminde alın üstü topuzu olarak nitelendirilen "Nodus Tipi" saç modası da görülmektedir (İnan ve Rosenbaum, 1966, s. 123 lev. 81 res. 3, 4; Fittschen ve Zanker, 1983, s. 1, 2, 3 lev. 1; Aurenhammer, 1988, s. 125 res. 2; Boschung, 2002, lev. 67 res. 3, 4). Ayrıca Caligula'nın kız kardeşi Iulia Drusilla döneminde alın üzerindeki saç buklelerinin ondüle edilmesiyle şekillendirilmiş yeni bir saç modası da bilinmektedir (Özgan, 2013, s. 103, 104 res. 106). Fakat Iulius - Claudiuslar Hanedanlığı dönemindeki resmi ve özel portrelerde patetik ifade ile birlikte fizyonomik özelliklerin idealize edilerek işlenmesi de söz 
konusudur (Erkoç, 2012, lev. 15, 40, 102). Bu yüzdendir ki Kayseri başındaki karakteristik özelliklerin gerçekçi verilmesi irdelediğim portre başını, bu dönem üslubundan ayırmaktadır. Flaviuslar Hanedanlığı'nın kurucusu Vespasian döneminde portre sanatında fizyonomik özellikler gerçekçi bir şekilde aktarılmaya başlanmıştır (Poulsen, 1974, s. 44, 45 lev. 16, 17). $\mathrm{Bu}$ sanat anlayışı Traian döneminin sonlarına kadar da devam ettirilmiştir (Smith vd., 2006, s. 209, 210, 211 lev. 69, 70, 71). Flaviuslar Hanedanlığ döneminde kadın portrelerinde Iulia Titi (West, 1941, lev. 7 res. 21; Zoridis, 1984, lev. 79) ve Domitia Longina (Wegner, 1966, lev. 55c, d; Varner, 1995, s. 204 res. 14) örneklerinde görüldüğü gibi saçtaki bal peteği olarak adlandırılan süngerimsi saç kütlesi ile birlikte oldukça ütopik görünümdeki çelenkvari saç kütlesi de uygulanmıştır. Traian döneminde de Pompeia Plotina (Delbrück, 1912, lev. 42), Ulpia Marciana (Comstock ve Vermeule, 1976, s. 220, 221 res. 350) ve Salonia Matidia (Bernoulli, 1891, lev. 35) portrelerindeki gibi kulaktan kulağa yüzeysel bir taç gibi alnı çevreleyen çift katmanlı saç kütlesiyle beraber diademvari saç modası da kullanılmıştır. Geç Traian döneminde de çok katmanlı örgülü saç kütlesi görülmektedir (İnan ve Rosenbaum, 1966, s. 163 lev. 115 res. 2). Böylelikle Flaviuslar Hanedanlığı'ndan Traian dönemine kadarki süreçte sürekli değişim gösteren saç modasına rağmen değişmeyen tek şey dolgun yüz örneğinde olduğu gibi karakteristik özelliklerin gerçekçi verilmesidir (Wegner, 1966, lev. 55c, d; İnan ve Rosenbaum, 1966, s. 163 lev. 115 res. 2; Varner, 1995, s. 204 res. 14). Hadrian döneminde de Vibia Sabina'nın "Augusta" unvanıyla onurlandırılması sonrasında portrelerinde "Ceres Tipi” kuaförlük modası işlenmiştir (Wegner, 1956, lev. 45; Özgan, 2013, s. 164). Yüzdeki karakteristik özellikler de idealize edilerek verilmiştir (Özgan, 2013, s. 163, 164, 165). Kayseri Müzesi’ndeki kadın portresinde ise Hadrian dönemi ve sonrasında görülen göz bebeği ve irisin işlenmemesi (Kleiner, 1992, s. 242 res. 206) ve fizyonomik özelliklerin de idealize edilerek verilmemesinden dolayı kadın başı, Erken Hadrian döneminden olmalıdır.

\section{Sonuc}

İrdelediğim kadın başındaki saç modası başta olmak üzere diğer fizyonomik ve stilistik özellikler 1şığında yapmış olduğum karşılaştırmalarla "Ceres Tipi” saç modasının uygulandığ1 Iulius - Claudiuslar Hanedanlığ tarihlendirilmediği gerekçeleriyle açıklanmıştır. Erken Hadrian dönemine verdiğim kadın başındaki fizyonomik özelliklerin idealize etkilerden uzak olması ve göz bebeği ve irisin de işlenmemesi kadın başını tarihlendirmemdeki en önemli etkenlerden bazılarıdır. Bu veriler 1şığında da Kayseri eseri, Erken Hadrian dönemi sonrasına tarihlendirilmesi mümkün olmayan özel bir portredir.

$\begin{array}{ll}\text { B. G } & \text { : Baş Genişliği } \\ \text { B. Y } & \text { : Baş Yüksekliği } \\ \text { Cm } & \text { : Santimetre } \\ \text { Env. No. } & \text { : Envanter Numarası } \\ \text { Lev. } & \text { : Levha } \\ \text { Res. } & \text { : Resim } \\ \text { S. } & \text { : Sayfa } \\ \text { Vd. } & \text { : Ve diğerleri }\end{array}$

Kisaltmalar ve Kaynakça

Aurenhammer, M. (1988). "Römische porträts aus Ephesos". II conferenza internazionale sul ritratto Romano ritratto ufficiale e ritratto privato, Roma 26-30 settembre 1984: 123130.

Bernoulli, J. J. (1891). Römische ikonographie: Die bildnisse der Römischen Kaiser II. Von Galba bis Commodus. Stuttgart, Berlin, Lepzig: Union Deutsche Verlagsgesellschaft. 
Boschung, D. (2002). Gens Augusta: Untersuchungen zu aufstellung, wirkung und bedeutung der statuengruppen des Julius-Cladiuschen Kaiserhauses. Germany: Verlag Philipp von Zabern-Mainz am Rhein.

Comstock, M. B. ve Vermeule, C. C. (1976). Sculpture in stone: The Greek, Roman and Etruscan collections of the Museum of Fine Arts Boston. Boston: Museum of Fine Arts.

Delbrück, R. (1912). Antike porträts. Bonn: A. Marcus \& E. Weber.

Erkoç, S. (2012). Anadolu'da Iulius-Claudiuslar dönemi portre sanatı. (Yayımlanmamış Doktora Tezi). Akdeniz Üniversitesi Sosyal Bilimler Enstitüsü, Antalya.

Fittschen, K. ve Zanker, P. (1983). Katalog der römischen porträts in den Capitolinischen Museen und den anderen kommunalen sammlungen der stadt Rom: Band III-text. West Germany: Philipp von Zabern, Mainz am Rhein.

Fittschen, K. ve Zanker, P. (1983). Katalog der römischen porträts in den Capitolinischen Museen und den anderen kommunalen sammlungen der stadt Rom: Band III-tafeln. West Germany: Philipp von Zabern, Mainz am Rhein.

İnan, J. ve Rosenbaum, E. (1966). Roman and early Byzantine portrait sculpture in Asia Minor. Londra: The Oxford University Press.

İnan, J. ve Rosenbaum, E. A. (1979). Römische und frühbyzantinische porträtplastik aus der Türkei-text. West Germany: Philipp von Zabern, Mainz am Rhein.

İnan, J. ve Rosenbaum, E. A. (1979). Römische und frühbyzantinische porträtplastik aus der Türkei-tafeln. West Germany: Philipp von Zabern, Mainz am Rhein.

Kleiner, D. E. E. (1992). Roman sculpture. New Haven: Yale University Press.

Özgan, R. (2013). Roma portre sanatı II. İstanbul: Ege Yayınlar1.

Poulsen, V. (1974). Les portraits Romains volume II: De Vespasien Á la basse-antiquité texte. Kopenhag: Ny Carlsberg.

Poulsen, V. (1974). Les Portraits Romains volume II: De Vespasien Á la basse-antiquité planches. Kopenhag: Ny Carlsberg.

Rumpf, A. (1941). Abhandlungen der preußischen akademie der wissenschaften: Antonia Augusta. Berlin: Verlag der Akademie der Wissenschaften.

Sadurska, A. (1972). Corpus signorum imperii Romani Pologne volume I: Les portraits Romains dans les collections Polonaises. Warszawa: PWN-éditions scientifiques de Pologne.

Smith, R. R. R., Dillon, S., Hallet, C. H., vd. (2006). Aphrodisias II: Roman portrait statuary from Aphrodisias. Mainz: Verlag Philipp von Zabern.

Varner, E. A. (1995). "Domitia Longina and the politics of portraiture". American Journal of Archaeolgy, 99,2: 187-206.

Zoridis, P. (1984). "Two new Roman portraits from Athens". American Journal of Archaeology, 88,4: 592-594.

Wegner, M. (1966). Das Römische herrscherbild: Die Flavier (Vespasian. Titus. Domitian. Nerva. Iulia Titi. Domitilla. Domitia). Berlin: Verlag Gebr. Mann.

West, R. (1941). Römische porträt-plastik II. Münih: F. Bruckmann K. G. 


\section{Ekler}

\section{Levha I}

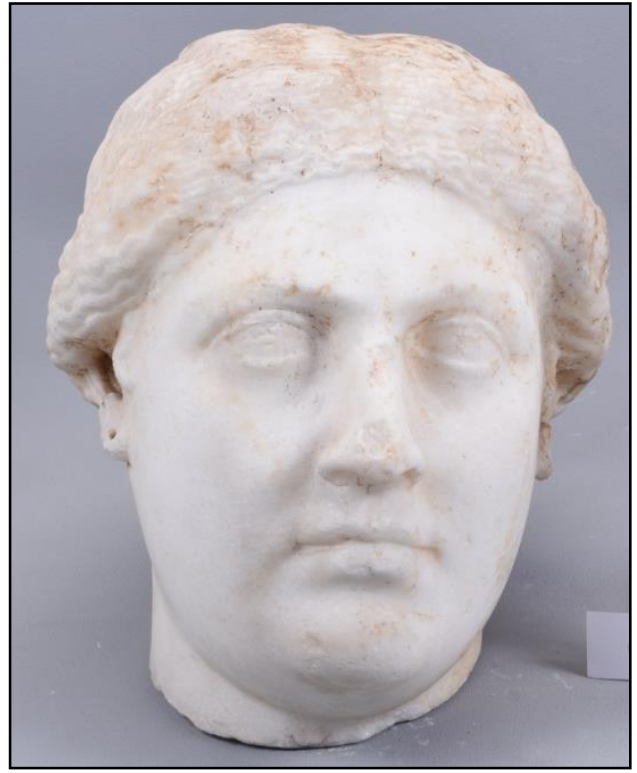

Res.1. Portre baş cepheden.

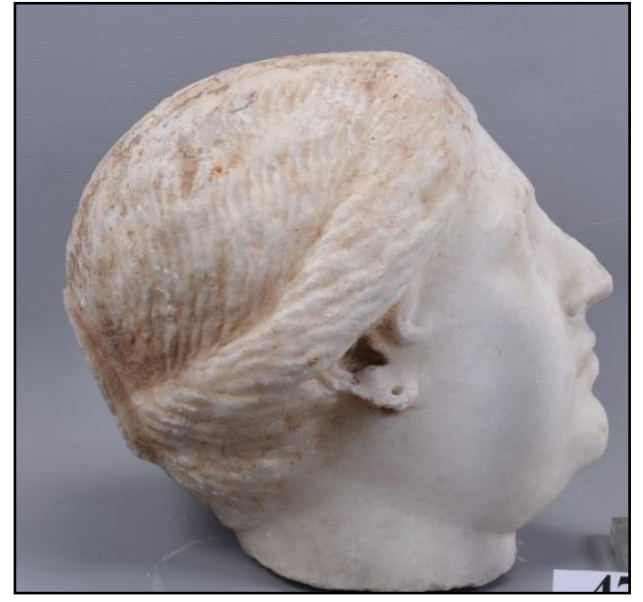

Res. 3. Portre baş sağ profil.

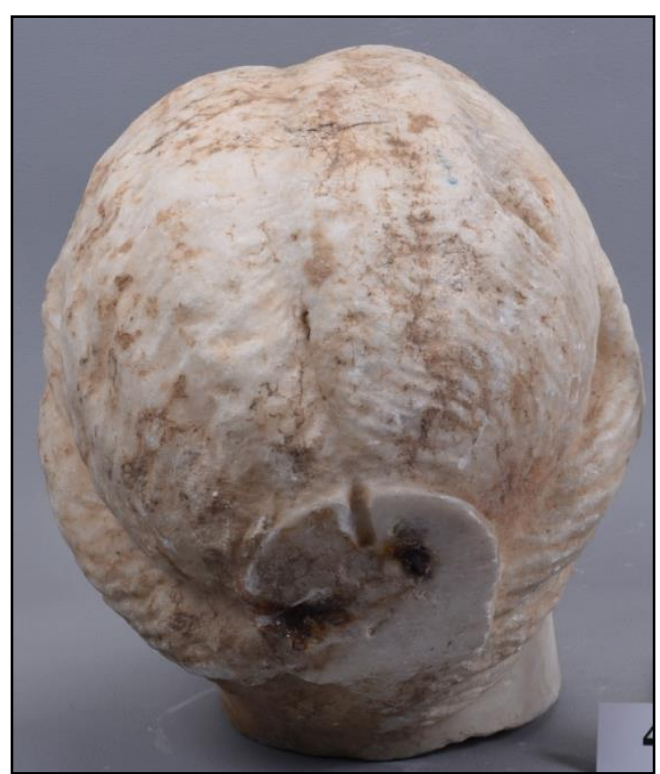

Res. 2. Portre baş arka profil.

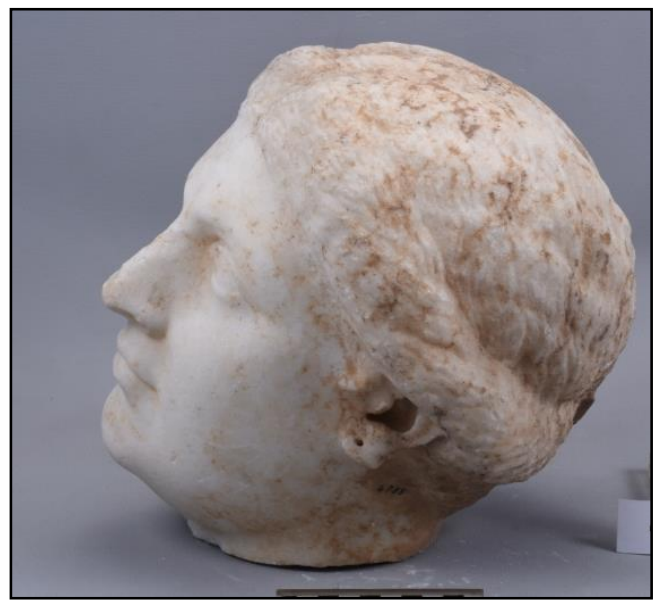

Res. 4. Portre baş sol profil.

Kaynak: Kayseri arkeoloji müzesi/Erken Hadrian dönemi özel kadın portresi, (Fotoğraf: Y. Arlı/2018). 